\title{
Reuna
}

\section{HONORÁRIOS DE AUDITORIA: ANÁLISE COMPARATIVA EM EMPRESAS LISTADAS NA BM\&FBOVESPA}

\section{AUDIT FEES: COMPARATIVE ANALYSIS IN LISTED COMPANIES BM \&FBOVESPA}

http://dx.doi.org/10.21714/2179-8834/2017v22n2p01-23

\author{
Alyssan Monteiro Binda \\ Universidade Federal do Espírito Santo, Brasil. \\ Endereço completo: : Av. Fernando Ferrari, 514 - Goiabeiras - Vitória - ES \\ Fone: +55 (27) 40092602 \\ E-mail: alyssanmonteirob@gmail.com \\ Vanessa Thompson Barros \\ Universidade Federal do Espírito Santo, Brasil. \\ Endereço completo: : Av. Fernando Ferrari, 514 - Goiabeiras - Vitória - ES \\ Fone: +55 (27) 40092602 \\ E-mail: vanessathompsonb@hotmail.com \\ Donizete Reina \\ Universidade Federal do Espírito Santo, Brasil. \\ Endereço completo: : Av. Fernando Ferrari, 514 - Goiabeiras - Vitória - ES \\ Fone: +55 (27) 40092602 \\ E-mail: donizete.reina@ufes.br \\ Lattes: http://lattes.cnpq.br/6775492728267435 \\ Diane Rossi Maximiano Reina \\ Professora da Universidade Federal do Espírito Santo, Brasil. \\ Endereço completo: Av. Fernando Ferrari, 514 - Goiabeiras - Vitória - ES \\ Fone: +55 (27) 40092602 \\ E-mail: diane.reina@ufes.br \\ Lattes: http://lattes.cnpq.br/5906583738243906

\section{Mirian Albert Pires} \\ Professora da Universidade Federal do Espírito Santo, Brasil. \\ Endereço completo: : Av. Fernando Ferrari, 514 - Goiabeiras - Vitória - ES \\ Fone: +55 (27) 40092602 \\ E-mail: mirianalbert@yahoo.com.br \\ Lattes: http://lattes.cnpq.br/6122825316477734
}

Submissão: 12 Ago. 2016 Publicação: 22 set. 2017. Sistema de avaliação: Double blind review. Centro Universitário UNA, Belo Horizonte - MG, Brasil. Editor geral Prof. Dr. Gustavo Quiroga Souki

Este artigo encontra-se disponível no endereço eletrônico:

http://revistas.una.br/index.php/reuna/article/view/799

http://dx.doi.org/10.21714/2179-8834/2017v22n2p01-23

\section{RESUMO}

Com a adoção da prática de governança corporativa, as empresas conseguem emitir sinais aos usuários externos com confiabilidade sobre suas informações. De acordo com a teoria da sinalização, as práticas e mecanismos de governança corporativa são formas de a empresa representar sinais, que estão se comunicando com o mercado. Neste contexto, este artigo apresenta o estudo realizado em investigar se a governança corporativa, praticada pelas empresas listadas na BM\&FBOVESPA, 
têm relação com os honorários de auditoria, analisando o tamanho da empresa, complexidade, se auditada por uma big four ou não, os gastos com honorários de auditoria, retorno sobre o ativo, alavancagem financeira, contas a receber e estoque como variáveis e os determinantes deste impacto. A pesquisa analisou uma amostra de 169 empresas referente ao ano de 2015, por meio da análise de estatística descritiva e a técnica econométrica de regressão linear múltipla. A pesquisa é descritiva, documental e com análise quantitativa. Foram utilizadas como hipótese de pesquisa as seguintes variáveis: governança corporativa (GovCorp), firma de auditoria (Big4), tamanho da empresa (Tam), complexidade (Subs), retorno sobre o ativo (ROA), alavancagem financeira (Alav), contas a receber (CtasRec) e estoque (Est) abordando a relação entre a variável dependente honorários de auditoria (HonAud). Concluiu-se que apenas as variáveis Big4, Tam e Alav possuem relação positiva e significativa com os honorários de auditoria. Portanto, rejeita-se a hipótese principal do estudo, pois não foi constatada relação positiva e significativa entre os níveis de Governança Corporativa e os honorários de auditoria contábil.

Palavras-chave: Honorários de Auditoria; Governança Corporativa; Teoria da Sinalização.

\begin{abstract}
With the adoption of the practice of corporate governance, companies can send signals to external users with reliability about their information. According to signaling theory, the practices and mechanisms of corporate governance, is the way the company represents signals that are communicating with the market. In this context, this article presents a study carried out to investigate whether the corporate governance practiced by the companies listed on BM \& FBOVESPA is related to audit fees, analyzing the size of the company, complexity, whether audited by a big four or not, fee expenses Audit, return on assets, financial leverage, accounts receivable and inventory as variables and the determinants of this impact. The research analyzed a sample of 169 companies referring to the year 2015 through the analysis of descriptive statistics and the econometric technique of multiple linear regression. The research is descriptive, documental and with quantitative analysis. The following variables were used as a research hypothesis: corporate governance (GovCorp), audit firm (Big4), company size (Tam), complexity (Subs), return on assets (ROA), financial leverage (CtasRec) and inventory (Est) approaching the relationship between the dependent variable audit fees (HonAud). It was concluded that only as variables Big4, Tam and Alav live positive and significant relationship with audit fees. Thus, the main hypothesis of the study is rejected, since there was no positive and significant relationship between the Corporate Governance levels and the accounting audit fees.
\end{abstract}

Keywords: Audit Fees; Corporate governance; Theory of Signs.

\title{
1 INTRODUÇÃO
}

A fim de oferecer informações de qualidade e confiança ao mercado, as empresas que adotam a prática de governança corporativa possuem maior destaque ao sinalizar os agentes econômicos com o objetivo de conseguir reconhecimento junto aos usuários externos. Inclusive, Jesus e Alberton (2007) reforçam que o processo de implementação da governança corporativa nas empresas de capital aberto traz 
melhor reconhecimento na hora de demonstrar transparência às organizações. Tal entendimento se baseia na argumentação de que sua importância é de tamanha grandeza, além do fato de que muitas empresas, que estão fazendo parte deste processo puderam perceber que suas ações foram mais bem avaliadas do que as que não aderiram à governança corporativa e que as boas práticas de governança geram para a empresa uma melhor perspectiva na administração dos negócios, no sentido de haver maior garantia nas tomadas de decisões para com o interesse dos acionistas, logo, acarretando aumento de valor para a sociedade.

Ademais, segundo Bortolon e Silva Junior (2015), considerando a importância e a confiança em que a governança corporativa é empregada, a ética e outros valores são proporcionados a um ambiente confiante, incluindo esforços de todas as partes e boas relações com os stakeholders relativos às ações da entidade e, consequentemente, gerando resultados dessas ações. Contudo, Ereira (2007) afirma que entre os agentes econômicos existe assimetria de informações, porém a função de transmissão de tais informações deve ser dos administradores e gestores para que as mesmas sejam dirigidas da melhor maneira aos demais agentes.

Em complemento, Dalmácio (2009) apresenta que as empresas, que adotam as práticas de governança corporativa, podem representar sinal positivo para com os usuários externos de acordo com a teoria da sinalização. Porém, as entidades terão de arcar com os devidos custos, chamados de custos de sinalização, pois obter a sinalização de mercado, através das práticas de governança corporativa, faz com que a empresa gere desembolsos, proporcionando a espera e a otimização de benefícios futuros, como adquirir mais investidores, por exemplo.

Por outro lado, Munhoz et al. (2014) evidenciaram que, com a obrigatoriedade das IFRS no Brasil, a complexidade da mão de obra dos auditores aumentou e, com isso, influenciou em seus honorários. Similarmente, Castro, Peleias e Silva (2014) também analisaram determinantes em que se entende que os honorários de auditoria têm haver com a complexidade da realização do serviço, ou seja, quanto mais complexo o serviço a ser executado, maior será o valor desembolsado com honorários de auditoria. Neste contexto, apresenta-se o problema de pesquisa: Qual a relação entre a governança corporativa e os honorários de auditoria em empresas brasileiras listadas na BM\&FBovespa?

O objetivo deste trabalho é investigar se a governança corporativa praticada pelas empresas listadas na BM\&FBOVESPA tem relação com os honorários de auditoria, analisando o tamanho da empresa, complexidade, se auditada por uma big four ou não, os gastos com honorários de auditoria, retorno sobre o ativo, alavancagem financeira, contas a receber e estoque como variáveis e os determinantes deste impacto. Pois, diante de um mercado com alta competitividade, os investidores prezam, cada vez mais, por credibilidade e confiabilidade nas informações, e a fim de obter tal reconhecimento, as empresas precisam investir em auditoria de boa qualidade, a fim de passar informações confiáveis ao mercado.

Tomando por base o apresentado, é possível inferir que a presente pesquisa se justifica pelo caráter de proporcionar uma pesquisa empírica, que busque discutir a adoção de práticas de governança corporativa e os horários pagos pelos serviços de auditoria, avaliando se haveria relação entre ambos, fato esse que poderia, consequentemente, influenciar na decisão, por parte de alguns gestores, em adotar essas práticas. Como contribuição, a investigação proporcionará uma discussão que trará à luz se algumas variáveis como tamanho da empresa, complexidade, se é auditada por uma big four ou não, os gastos com honorários de auditoria, retorno 
sobre o ativo, alavancagem financeira, contas a receber e estoques têm relação com a adoção de práticas de governança corporativa.

Apresenta-se, ainda, que este estudo se divide em cinco seções. A próxima seção apresenta a fundamentação teórica e as hipóteses da pesquisa. Em seguida, encontra-se metodologia utilizada para o presente estudo. Já a quarta seção demonstra os resultados alcançados. Por sua vez, a última seção expõe as conclusões do estudo e as sugestões para pesquisas futuras.

\section{FUNDAMENTAÇÃO TEÓRICA}

Nesta seção se apresenta o embasamento teórico sobre a Auditoria, os Honorários de Auditoria, a Teoria da Sinalização, a Governança Corporativa e as principais referências utilizadas como base neste estudo.

\subsection{Auditoria}

Para a realização do trabalho de auditoria, é fundamental que o auditor encontre um ambiente que sinta confiança em opinar sobre as operações realizadas pela companhia, procurando sempre respeitar a legislação vigente e as práticas contábeis geralmente aceitas. Contudo, para ele emitir o seu parecer, é necessário que o auditor faça um levantamento de todo o trabalho, que será necessário para essa atividade de avaliação e julgamento (CORDEIRO, 2012).

Sendo assim, para tal tarefa existe uma vasta literatura que orienta os auditores na realização desse processo (CORDEIRO, 2012; PEREZ JÚNIOR, 2012; YOSHITAKE, 2012). Todavia, essa atividade requer um trabalho minucioso, exigindo um planejamento prévio, levando em consideração os controles internos adotados pela empresa, o sistema de informação existente e os riscos inerentes ao trabalho a ser executado (LINS, 2014).

Essa característica demonstra o quão subjetivo pode ser a atividade de auditoria, instigando a realização de pesquisas ligadas a esse ramo do conhecimento contábil. Essa realidade justifica a existência de vários trabalhos científicos, que têm como foco a evolução histórica da auditoria (RICARDINO; CARVALHO, 2004), o processo de amostragem (SANTOS et al., 2005), a qualidade dos pareceres (SANTOS et al., 2009; CUNHA et al., 2010; DAMASCENA et al., 2011), a qualidade da produção acadêmica (OLIVEIRA; CARVALHO, 2008), o gerenciamento de resultados (ALMEIDA; ALMEIDA, 2009; AZEVEDO; COSTA, 2012), a realização do rodízio de firmas de auditoria (OLIVEIRA; SANTOS, 2007; FORMIGONI et al., 2009), bem como a auditoria interna e a minimização de fraudes (PEREIRA; NASCIMENTO, 2005).

Contudo, outro tema de pesquisa também tem se destacado, sendo este relacionado com a investigação dos fatores, que poderiam influenciar o valor cobrado pelo trabalho de auditoria (HAY et al., 2006). Essa constatação se justifica pelo fato desse serviço ser minucioso e requerer que o auditor leve em considerações algumas variáveis ligadas às características da firma para a determinação do valor dessa atividade. 


\subsection{Honorários de Auditoria}

Apesar de existirem orientações oriundas do Conselho Federal de Contabilidade (CFC) a respeito da cobrança dos honorários de auditoria (CFC, 2012), o arcabouço econômico aponta que esses honorários refletem os custos econômicos e a eficiência do auditor (SIMUNIC; STEIN, 1996). Todavia, esses custos econômicos poderiam se relacionar a itens ligados com a característica de cada firma, conforme documentado pela literatura internacional (HAY et al., 2006). Essa constatação se deve a um trabalho de meta-análise realizada pelos referidos autores, considerando uma literatura de 25 anos, sendo possível apontar as pesquisas, que tratavam sobre honorários de auditoria e evidenciavam os fatores que poderiam influenciar na sua determinação.

Como resultado, eles ressaltaram que a literatura mais recente demonstrava existência de estudos relacionando os honorários de auditoria com variáveis como tamanho da firma, complexidade, risco inerente, lucratividade da empresa, alavancagem, forma de propriedade, controle interno, governança corporativa, setor da empresa e o fato de ser ou não uma grande empresa de auditoria. Todavia, a maior parte dessas discussões se concentrava sobre as variáveis: tamanho, complexidade e risco inerente, ficando evidente a necessidade de execução de análises, que explorassem mais detalhadamente as outras variáveis.

Essa realidade traz à tona autores que são defensores da intensificação de estudos que deem destaque para a importância de práticas de governança corporativa e como a sua existência pode influenciar, negativamente, nos valores cobrados pelos auditores (YATIM et al., 2006; HAY et al., 2008). Em meio a tais apontamentos, torna-se possível inferir que investigações ligadas aos honorários cobrados pela auditoria seriam frutíferas e trariam contribuições para essa área de estudo (CARCELLO et al., 2002).

\subsection{Teoria da Sinalização}

Considerando que a adoção de práticas de governança corporativa pode representar sinal positivo para com os usuários externos, tendo a sua fundamentação na teoria da sinalização (DALMÁCIO, 2009), torna-se necessário um aprofundamento sobre essa temática. Inclusive, Kirmani e Rao (2000) consideraram como sinais as ações tomadas em uma transação de uma das partes, a fim de revelar qualificações verdadeiras, podendo ser realizada de várias formas, como marcas, preços, gastos com propaganda e até reputação no mercado. Beuren e Klann (2011) também destacam que a divulgação de índices contábeis como uma sinalização.

Por sua vez, Marques e Conde (2000 apud SILVA) afirmam que as informações quando chegam aos agentes são assimétricas, sendo dever dos gestores passar as informações através de um sinal, pois os mesmos são os que possuem informações propícias sobre a questão. Já para Spence (1973), a teoria da sinalização também serve para explicar o comportamento do mercado de trabalho, através da assimetria informacional, na qual se pode transmitir aos outros indivíduos as informações, melhorando a qualidade das informações e tornando-as de fácil compreensão. Também afirma que através da teoria da sinalização, a empresa terá melhor divulgação de informação, a fim de transmitir ao mercado, e que esse deve ser papel dos administradores, por possuírem informações superiores aos demais agentes, contribuindo com informações fidedignas. 
Dalmácio (2009) afirma ainda que, de acordo com teoria da sinalização, as práticas e mecanismos de governança corporativa são a forma de a empresa representar sinais de que estão se comunicando com o mercado. Para a emissão desses sinais, a empresa precisa incorrer com custos de sinalização. Ainda concorda que é um elemento de muita importância para a sinalização no mercado, pois assim as empresas fornecerão informações propícias a chegarem até os analistas de investimentos, investidores, credores, através da sinalização, auxiliando nas decisões na hora do investimento sob condições de incerteza.

Ereira (2007) destaca que a escolha da política contábil tem ligação com a teoria da sinalização, pois afirma que as empresas com maior qualidade, em seus resultados, optam por políticas contábeis, que demonstrem superioridade quanto a sua relevância, ao contrário das empresas com baixa qualidade, pois estas escolhem métodos a fim de camuflar sua qualidade inferior.

Em complemento, Beuren e Klann (2011) relatam que em relação à lucratividade da empresa é sugerido que as que possuem bom desempenho sinalizem essa qualidade aos investidores, conforme informa a teoria da sinalização, pois afirmam que junto da teoria de agência possa haver influência na divulgação de indicadores de desempenho voluntariamente nos índices de lucratividade ao mercado.

Antunes e Procianoy (2003) contribuíram ao evidenciar em pesquisa que a variação do ativo permanente da entidade é considerada como uma sinalização onerosa para os impactos das decisões de investimentos das empresas referentes ao preço das ações no mercado de capitais. Também destaca que as informações sinalizadas com credibilidade são levadas em consideração com a probabilidade de as entidades cumprirem o que é informado aos agentes externos (stakeholders).

\subsection{Governança Corporativa}

O Instituto Brasileiro de Governança Corporativa (IBGC) conceitua Governança Corporativa como "sistema pelo qual as organizações são dirigidas, monitoradas e incentivadas, envolvendo os relacionamentos entre proprietários, Conselho de Administração, Diretoria e órgãos de controle" (IBGC, 2010, p. 19).

Para Vieira et al. (2011), a governança corporativa tem relação entre a gestão de uma entidade, fazendo com que os empresários tenham interesse, quando percebem que através da utilização de suas práticas é possível resolver conflitos de interesses entre acionistas e gestores.

Já Silveira, Perobelli e Barros (2008) argumentaram que a adoção da prática de governança corporativa pode, ao mesmo tempo, determinar aquisição de recursos próprios e de terceiros e serem influenciadas pela estrutura de capital.

Segundo Garcia (2005), o conflito de agência e de gestores é superado com o surgimento da prática de governança corporativa, resultando da separação das propriedades e gestão da entidade. Ainda afirma que tal conflito de interesses, assume distintas características na estrutura de propriedades em função das empresas.

Pode-se entender, então, que a prática de governança corporativa é regida por princípios, como transparência, equidade, prestação de contas, cumprimento das leis e a ética na condução dos negócios de empresas (responsabilidade corporativa), de governos e entidades não governamentais, conforme Quadro 01. 


\section{Quadro 01 - Princípios de Governança Corporativa}

\section{Princípios}

Transparência

Equidade

Prestação

Contas

(accountability)

Responsabilidade

Corporativa

\section{Descrição}

Desejo disponibilizar aos interessados as informações que sejam de seu interesse. A transparência resulta em clima de confiança, seja internamente ou a terceiros. Não devendo restringir-se quanto ao desempenho econômico-financeiro, contemplando aos demais fatores que norteiam ação gerencial conduzindo a criação de valor.

É o tratamento justo de todos os sócios e de demais interessados (stakeholders), em que atitudes ou políticas discriminatórias sob qualquer pretexto se apresentam inaceitáveis.

de Os agentes de governança devem prestar contas de sua atuação devendo assumir integralmente com as consequências de seus atos e omissões.

Os agentes devem zelar pela sustentabilidade das organizações, visando sua longevidade, em consideração de ordem social e ambiental na definição dos negócios e operações.

Fonte: Adaptado IBGC (2016)

Os segmentos empregados na listagem da BM\&FBovespa foram criados no momento em que foi percebido que, para desenvolver o mercado de capitais do Brasil, era preciso segmentar as empresas aos seus diferentes perfis, sendo estes: Bovespa Mais, Bovespa Mais Nível 2, Novo Mercado, Nível 2 e Nível 1. Todos estes segmentos prezam por regras de governança corporativa, que vão além das obrigações das entidades sobre a lei das sociedades por ações, com o intuito de tornar a avaliação melhor, para quem decidir aderir, voluntariamente um desses segmentos (BM\&FBovespa, 2016). No Quadro 02 está apresentada a classificação dos níveis:

\section{Quadro 02 - Níveis de Governança Corporativa}

\section{Nível de \\ Governança \\ Corporativa}

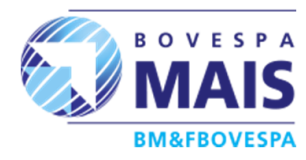

MAISNível2

\section{Descrição}

Esse segmento tem como objetivo fomentar o crescimento de pequenas e médias empresas via mercado de capitais, permitindo que a empresa se prepare, de forma adequada, implementando elevados padrões de governança corporativa e transparência com o mercado aumentando sua visibilidade para os investidores.

O segmento de listagem Bovespa Mais Nível 2 é similar ao Bovespa Mais, porém com algumas exceções. As empresas listadas têm o direito de manter ações preferenciais (PN). As ações preferenciais ainda dão o direito de voto aos acionistas em situações críticas. 
NOVO

MERCADO

BM\&FBOVESPA

Nível de

Governança

Corporativa

NÍVEL 2

BM\&FBOVESPA

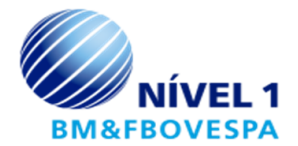

O Novo Mercado se refere à negociação de ações de empresas que adotam, voluntariamente, práticas de governança corporativa adicionais às que são exigidas pela legislação brasileira, conduzindo as empresas ao mais elevado padrão de governança corporativa. As empresas listadas nesse segmento podem emitir apenas ações com direito de voto, as chamadas ações ordinárias $(\mathrm{ON})$.

\section{Descrição}

Similar ao Novo Mercado, as empresas têm o direito de manter ações preferenciais (PN) que dão o direito de voto aos acionistas em situações críticas, como a aprovação de fusões e incorporações da empresa e contratos entre o acionista controlador e a empresa, sempre que essas decisões estiverem sujeitas à aprovação na assembleia de acionistas.

As empresas do segmento Nível 1 devem adotar práticas que favoreçam a transparência e o acesso às informações pelos investidores.

Fonte: Adaptado da BM\&FBovespa (2016)

Para Zibordi (2007), a adesão de alguns dos níveis de governança corporativa é capaz de gerar diversos benefícios aos envolvidos. Para os investidores, é permitido maior capacidade de percepção das ações, melhoria em seu processamento de acompanhamento e fiscalização dos negócios oferece aos acionistas maior proteção sobre seus diretos, reduzindo os riscos interligados ao investimento. Para as companhias, têm a possibilidade de melhorar a imagem institucional, aumentar as ações através de mais demandas, ações valorizadas e o capital com menor custo.

Conforme Lima et al. (2014), a governança corporativa surgiu com o intuito de diminuir os conflitos de agência, incrementando como benefícios, valor de mercado nas empresas que adotam as práticas em maiores níveis. Ainda afirma que estudos feitos no Brasil e internacionalmente têm refletido benefícios nas entidades com boas práticas em seu desempenho econômico.

Segundo Martinez (2010), as práticas de governança corporativa vêm ganhando maior reconhecimento e valorização no mercado internacional, devido aos escândalos contábeis ocorridos.

\subsection{Estudos Assemelhados}

Com o objetivo de localizar informações através de estudos anteriores identificando tendências e relação entre governança corporativa e os honorários de auditoria, foram realizadas buscas em periódicos, tomando por foco aqueles que eram brasileiros e ligados a contabilidade e a administração. As palavras utilizadas nas buscas foram "honorários de auditoria", "custos de auditoria", "auditoria", "governança corporativa" e "empresas da BM\&FBOVESPA". Os resultados obtidos formaram-se de pesquisas realizadas com base no assunto a ser estudado, e com as informações necessárias para a realização do mesmo. 
Castro, Peleias e Silva (2014) analisaram os determinantes dos honorários de auditoria, em um estudo realizado nas empresas listadas na BM\&FBOVESPA com dados de 2012. Foi concluído que a relação cobrada aos honorários é medida pela remuneração dos administradores e, conforme a complexidade da realização do serviço, com a hipótese de que clientes mais complexos exigem maior esforço em seu trabalho e, consequentemente, maior remuneração para com os honorários.

A pesquisa realizada por Martinez e Moraes (2014) relaciona a remuneração dos auditores com a qualidade da auditoria realizada nas 300 maiores empresas listadas na Bovespa, no período de 2009 a 2012. Foram apresentadas formas de observar a qualidade dos serviços realizados, comparando a remuneração cobrada pelos auditores, versus a complexidade de serviços. O resultado obtido, por meio de comparações de dados, demonstrou que o gerenciamento mais agressivo ocorreu, predominantemente, nas empresas em que o pagamento dos honorários foi menor do que o desejado, e o serviço, consequentemente, realizado de uma forma inferior ao profissional, que obtém maiores honorários pagos.

Oliveira, Souza e Vieira (2004) analisaram o processo para a estimativa de custos e a formação de preços nas empresas de auditoria. Para obter o resultado, foi utilizado o processo de estimação de custos e formação de preços, permitindo identificar fatores e condições, que influenciam a tomada de decisão. As pesquisas foram divididas em dois grupos: fatores internos (a partir de informações internas da empresa) e externos (determinados pela variação do ambiente em que a empresa está inserida).

A pesquisa de Hallak e Silva (2012) demonstrou determinantes, que causam maior desembolso com auditoria e consultoria prestada por auditores externos, em empresas brasileiras listadas, em 2009 na BM\&FBOVESPA, e identificaram uma relação positiva entre as boas práticas de governança corporativa e gastos de auditoria, pois estas gastam mais com auditoria, visto que buscam maior qualidade, transparência e confiabilidade, reduzindo a assimetria informacional dada aos stakeholders. O resultado possibilitou que as boas práticas de governança corporativa reduzam os riscos de auditoria e, consequentemente, o preço exigido. Como conclusão, as firmas de auditoria levam em consideração para precificação de seus serviços as características, como: tamanho do cliente e o nível de governança. Beck, Cunha e Franz (2015) verificaram o custo dos honorários de auditoria com base na maior qualidade das informações financeiras em empresas familiares e não familiares listadas na BM\&FBOVESPA, no período de 2009 a 2011, no intuído de fundamentar a hipótese de que os auditores cobram honorários mais baixos de empresas familiares em relação às não familiares. A pesquisa apresentou, de fato, valores pagos a maior por serviços de auditoria em empresas não familiares do que em familiares. No entanto, a hipótese foi rejeitada pelos autores, que concluíram que a variável "empresa Familiar" obtida pelo teste de médias e do modelo de regressão, não obteve resultado estatisticamente significativo para sustentar a hipótese.

Conforme exposto por Bortolon, Sarlo Neto e Santos (2013), no estudo analisando a relação entre governança corporativa, custos de auditoria e serviços suplementares de auditoria, os resultados apontaram para uma relação negativa entre governança corporativa e os custos de auditoria devido ao predomínio do risco em empresas brasileiras. Também foi levado em consideração que a contratação de uma Big Four impacta, quando o serviço de auditoria é prestado por estas, pois o custo é maior. Além do mais, melhores práticas de governança minimizam os riscos acarretando redução dos valores cobrados para serviço da auditoria. 
A pesquisa realizada por Lima et al. (2015) analisou os indicadores de desempenho entre os três níveis de mercado da BM\&FBOVESPA com a contribuição da governança corporativa, em relação às empresas que adotam e as que não adotam a prática. Foi evidenciado que as empresas que adotam o sistema de governança são mais sofisticadas e desempenham melhores performances econômicas. Melo et al. (2013) também consideraram que a governança corporativa é contribuinte para o desempenho da organização e para o retorno de seus acionistas, e que o desempenho empresarial nas empresas de capital aberto é considerado, quando o efeito é proporcionado nos ativos da empresa.

Similarmente, Martinez, Lessa e Moraes (2014) utilizaram uma amostra de 300 empresas listadas na BM\&FBOVESPA de 2009 a 2011, em uma pesquisa, relacionando a agressividade tributária das empresas e os honorários de auditoria, concluíram que empresas, que adotam as boas práticas de governança corporativa, estreitam os riscos de auditoria e como consequência os seus honorários.

Para Camargo, Pepinelli e Camacho (2006), os riscos de um parecer de auditoria são bem prováveis de ocorrer, pois ainda é difícil obter um resultado livre de riscos. Pelo trabalho ser feito através de amostras, pode acontecer de uma demonstração ser elaborada inadequadamente, não representando a realidade da empresa. Esses riscos podem surgir por meio de fatores como o aumento da estrutura das empresas, a busca constante por competitividade e lucratividade, os usuários e até mesmo em interesses particulares, determinando que o ambiente se torne propenso ao surgimento de fraudes e erros por conta da complexidade dos fatores.

Segundo Dalmácio (2009), esses problemas podem ser identificados e reduzidos pela sinalização de informações, através da teoria da sinalização. Seu objetivo é demonstrar os mecanismos, discriminando os sinais dos problemas de assimetria informacional e, com isso, podendo reduzir através de mais informações sinalizadas, sendo capaz de alterar crenças com a transmissão de informações aos usuários desta com o intuito de eliminar ou diminuir essa assimetria, com isso as mesmas são capazes de fornecer informações necessárias, a fim de atrair mais recursos e investimentos para si através da sinalização.

\section{METODOLOGIA DA PESQUISA 3.1 Construções das Hipóteses}

O risco e a complexidade dos auditados são os dois fatores principais para a precificação dos serviços de auditoria, segundo Hallak e Silva (2012). Já Jesus e Alberton (2007) concluem que as características notadas em relação à Governança Corporativa, principalmente, a transparência, a integridade e a prestação responsável de contas alteram, positivamente, o perfil das empresas diante do mercado de capitais, auxiliando os investidores na realização de negócios com menores riscos, devido a melhores práticas contábeis e de auditoria.

Martinez, Lessa e Moraes (2014) afirmam que há uma relação positiva entre risco de manipulação dos resultados e aumento dos honorários de auditoria com a baixa qualidade de governança corporativa. Por outro lado, Bortolon, Sarlo Neto e Santos (2013) sugerem que melhores práticas de governança corporativa reduziram os riscos da auditoria e, por consequência, seus honorários.

Entretanto, para Hallak e Silva (2012), empresas com melhores níveis de governança corporativa gastam mais com auditoria, por exigir mais qualidade, transparência e confiabilidade reduzindo a assimetria informacional dada aos 
stakeholders. Segundo Dalmácio (2009), o objetivo é demonstrar os mecanismos, discriminando os sinais dos problemas de assimetria informacional e, com isso, podendo reduzir por intermédio de mais informações sinalizadas, sendo capaz de alterar crenças com a transmissão de informações aos usuários da informação com o intuito de eliminar ou diminuir essa assimetria, com isso as mesmas são capazes de fornecer informações necessárias, a fim de atrair mais recursos e investimentos para si através da sinalização.

"Sendo assim, a auditoria contábil pode ser considerada como uma técnica ou uma tecnologia que será aplicada sobre os registros, as demonstrações e os informes contábeis visando apresentar um parecer sobre sua exatidão e veracidade" (JESUS; ALBERTON, 2007, p. 74). A governança corporativa, sendo um meio de sinalização ao mercado, como criação de valor, necessita garantir o rigor de suas práticas para que haja credibilidade em suas informações. Com isso, ela pode ser considerada como um custo de sinalização, pois as empresas necessitam dos serviços de auditoria para que realizem suas atividades com mais rigor, podendo causar impacto nos honorários de auditoria, por conta do serviço mais rígido a ser prestado.

Assim, estabeleceu-se a primeira hipótese de pesquisa:

H1: O nível de governança corporativa possui relação positiva e significativa com os honorários de auditoria.

Por conseguinte, estudos realizados demonstraram que as variáveis: Big Four, tamanho, complexidade, Retorno sobre ativo (ROA), alavancagem, contas a receber e estoques possuem influência sobre os honorários de auditoria. Quando a auditoria independente é realizada por uma firma Big Four, observou-se que há uma relação positiva sobre os honorários de auditoria (Castro, Peleias e Silva, 2014). Hallak e Silva (2012) constataram que empresas que possuem melhores práticas de governança corporativa tendem a desembolsar maiores despesas com auditoria e consultoria, pois contratam mais firmas Big Four, colaborando com a pesquisa de Bortolon, Sarlo Neto e Santos (2013) que a contratação de uma Big Four aumenta os custos com auditoria (Beck, Cunha e Franz, 2015). Para Castro, Peleias e Silva (2014), as firmas Big Four possuem equipes de qualidade e aplicam melhores procedimentos, acarretando em maiores honorários.

Quanto ao tamanho da empresa auditada, Marques et al. (2014) associaram a variável como a principal determinante dos valores pagos, em honorários de auditoria, devido a quantidade de trabalho despendida para a execução. Hallak e Silva (2012) ressaltam que quanto maior a empresa, mais complexo é o serviço e mais horas são exigidas para sua conclusão, fazendo com que as firmas de auditoria cobrem honorários maiores de empresas grandes, comparado a empresas pequenas, criando uma relação positiva entre tamanho da empresa e honorários de auditoria.

Segundo Castro, Peleias e Silva (2014), a relação positiva e significativa entre tamanho dos clientes e honorários de auditoria está relacionado à capacidade financeira destes clientes e a oportunidade comercial do auditor. Além disso, quanto maior o tamanho da empresa em relação ao seu faturamento, se pode observar que maiores foram os honorários pagos aos auditores (MUNHOZ et al., 2014).

No que tange a complexidade, para Martinez e Moraes (2014), uma grande quantidade de ativos são sinônimos de complexidade devido a maior dificuldade para a realização do trabalho, indicando que há uma tendência dos auditores em cobrar honorários mais caros para estas empresas. 
Castro, Peleias e Silva (2014) utilizaram a variável: Remuneração dos administradores (RA) para analisar a complexidade das empresas em relação aos honorários de auditoria, apresentando resultados positivos para clientes, que exigem maior esforço, por parte dos auditores, devido a sua complexidade e, por consequência, maiores honorários. Munhoz et al. (2014) evidenciaram que com a obrigatoriedade das IFRS no Brasil, a complexidade da mão de obra dos auditores aumentou refletindo em maiores honorários de auditoria.

Os honorários de auditoria estão diretamente relacionados com o tamanho e complexidade da empresa auditada e o risco assumido pela empresa de auditoria (BECK, CUNHA; FRANZ, 2015). Martinez, Lessa e Moraes (2014) apontaram uma relação negativa entre a variável $\mathrm{ROA}$ e os honorários. Indicando que quanto melhor a saúde financeira do cliente, menor o desembolso com honorários de auditoria.

Quanto à alavancagem, nos estudos de Hallak e Silva (2012) e Martinez e Moraes (2014), não foi evidenciado relação estatisticamente significativa entre a variável alavancagem e o preço cobrado pelos honorários. Para Castro, Peleias e Silva (2014), o resultado sugere que os honorários cobrados tendem a ser menores, pelo fato da pressão imposta pelo cliente, com problemas financeiros, sobre os auditores para terem menores custos com auditoria.

Martinez e Moraes (2014) utilizaram a variável ARINV (soma das contas a receber e inventário sobre o ativo total) e pode-se assimilar que os auditores necessitam realizar um maior número de testes, circularização e inventário acarretando em maiores honorários. Entretanto, na pesquisa, os autores concluem que, no Brasil, o cliente ter contas e receber e itens no estoque não fazem com que estes clientes paguem maiores honorários.

Com base nestas considerações foram formuladas as demais hipóteses de pesquisa conforme Quadro 03.

\section{Quadro 03 - Hipóteses da pesquisa}

\begin{tabular}{l|c}
\hline \multicolumn{1}{c|}{ Hipóteses da pesquisa } & $\begin{array}{c}\text { Relação } \\
\text { esperada }\end{array}$ \\
\hline $\begin{array}{l}\mathrm{H} 2 \mathrm{a}-\mathrm{A} \text { firma de auditoria big four possui relação positiva e significativa com os } \\
\text { honorários de auditoria }\end{array}$ & + \\
\hline $\begin{array}{l}\mathrm{H} 2 \mathrm{~b}-\mathrm{O} \text { tamanho da empresa possui relação positiva e significativa com os } \\
\text { honorários de auditoria }\end{array}$ & + \\
\hline $\begin{array}{l}\mathrm{H} 2 \mathrm{c}-\mathrm{A} \text { complexidade da empresa possui relação positiva e significativa com os } \\
\text { honorários de auditoria }\end{array}$ & + \\
\hline $\begin{array}{l}\mathrm{H} 2 \mathrm{~d}-\mathrm{A} \text { rentabilidade do ativo possui relação positiva e significativa com os } \\
\text { honorários de auditoria }\end{array}$ & + \\
\hline $\begin{array}{l}\mathrm{H} 2 \mathrm{e}-\mathrm{A} \text { alavancagem da empresa possui relação positiva e significativa com os } \\
\text { honorários de auditoria }\end{array}$ & + \\
\hline $\begin{array}{l}\mathrm{H} 2 f-\mathrm{O} \text { valor de contas a receber possui relação positiva e significativa com os } \\
\text { honorários de auditoria }\end{array}$ & + \\
\hline $\begin{array}{l}\mathrm{H} 2 \mathrm{~g}-\mathrm{O} \text { estoque possui relação positiva e significativa com os honorários de } \\
\text { auditoria }\end{array}$ & + \\
\hline
\end{tabular}




\subsection{Amostras e Variáveis da Pesquisa}

A pesquisa realizada é classificada como documental, descritiva e abordada como qualitativa, buscando evidenciar seus resultados por intermédio das empresas listadas na BM\&FBovespa com segmentos de listagem do Nível 1, Nível 2 e Novo Mercado. Primeiramente, foi preciso classificar e dividir o número de empresas por segmento de listagem. Seguindo para a relação das variáveis, informando onde foram coletados seus dados contábeis, sua descrição e autoria. Em seguida, foram realizadas as tabulações por meio de estatística descritiva e regressão linear múltipla.

A população foi formada pelas empresas listadas na BM\&Fbovespa, por intermédio dos segmentos de Nível 1, Nível 2 e Novo Mercado com informações e variáveis referentes ao período de 2015 . Foram retiradas da amostra as entidades Bancárias, pois estas entidades não continham todas as informações necessárias para análise da pesquisa, o que poderia distorcer os resultados da pesquisa. Da população foram totalizadas 169 empresas para amostra, distribuídas em seus respectivos níveis, conforme mencionado no Quadro 04.

Quadro 04 - Amostra distribuída por segmento

\begin{tabular}{lc}
\hline \multicolumn{1}{c}{ Segmento de Listagem } & Número de Empresas \\
\hline Nível 1 & 25 \\
Nível 2 & 16 \\
Novo Mercado & 128 \\
Total & 169 \\
\hline
\end{tabular}

Fonte: Dados da pesquisa.

Os dados necessários para obter as informações sobre suas variáveis apresentadas no quadro 05 foram coletadas na base de dados do sítio Comdinheiro para informações referentes ao tamanho da empresa, empresa de auditoria (se big four ou não), retorno sobre o ativo, alavancagem, contas a receber e estoques. No sítio da BM\&FBovespa se verificou o nível de Governança Corporativa e nos Formulários de Referência os honorários de auditoria pagos no ano e a complexidade dos serviços prestados. Os dados utilizados são referentes ao ano de 2015 e a coleta dos dados ocorreu entre junho e julho de 2016.

No Quadro 05 se apresenta descrito como foram calculadas as variáveis do estudo.

\section{Quadro 05 - Variáveis do estudo (continua)}

\begin{tabular}{|c|c|c|}
\hline Variável & Descrição & Referências \\
\hline \multicolumn{3}{|c|}{ Variável dependente } \\
\hline $\begin{array}{l}\text { Honorários de } \\
\text { Auditoria (HonAud) }\end{array}$ & $\begin{array}{l}\text { Logaritmo natural do valor pago aos } \\
\text { honorários de auditoria no ano }\end{array}$ & $\begin{array}{lll}\text { Hallak e Silva } \\
(2012), & \text { Bortolon, } \\
\text { Sarlo Neto e } \\
\text { Santos } & (2013) . \\
\end{array}$ \\
\hline \multicolumn{3}{|l|}{ Variável independente } \\
\hline $\begin{array}{l}\text { Governança } \\
\text { Corporativa } \\
\text { (GovCorp) }\end{array}$ & $\begin{array}{l}\text { Variável dummy: } 1 \text { para N1, } 2 \text { para N2, e } 3 \\
\text { para NM e } 0 \text { caso não seja }\end{array}$ & $\begin{array}{l}\text { Hallak e Silva } \\
\text { (2012), Bortolon, } \\
\text { Sarlo Neto e }\end{array}$ \\
\hline
\end{tabular}

REUNA, Belo Hor izonte - MG, Brasil, v.22, n.2, p.0123, Abr. - J un. 2017 - ISSN 2 279-8834 


\begin{tabular}{|c|c|c|}
\hline & & Santos (2013). \\
\hline $\begin{array}{l}\text { Firma de Auditoria } \\
\text { (Big4) }\end{array}$ & $\begin{array}{l}\text { Variável dummy: } 1 \text { se auditada por Big } \\
\text { Four e } 0 \text { caso não seja, ou não apresentar }\end{array}$ & $\begin{array}{l}\text { Bortolon, Sarlo } \\
\text { Neto e Santos } \\
(2013) \text {. }\end{array}$ \\
\hline $\begin{array}{l}\text { Tamanho da } \\
\text { Empresa (Tam) }\end{array}$ & $\begin{array}{l}\text { Logaritmo natural do ativo total da } \\
\text { entidade }\end{array}$ & $\begin{array}{lll}\text { Hallak } & \text { e Silva } \\
(2012) & & \end{array}$ \\
\hline Complexidade (Subs) & \begin{tabular}{|l|l|}
$\begin{array}{l}\text { Logaritmo natural do número de } \\
\text { subsidiárias consolidadas }\end{array}$ \\
\end{tabular} & 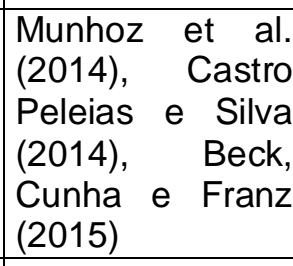 \\
\hline $\begin{array}{l}\text { Retorno sobre o ativo } \\
\text { (ROA) }\end{array}$ & $\begin{array}{l}\text { Logaritmo natural do Lucro Líquido/Ativo } \\
\text { Total }\end{array}$ & $\begin{array}{l}\text { Martinez, Lessa } \\
\text { e Moraes (2014). }\end{array}$ \\
\hline $\begin{array}{l}\text { Alavancagem } \\
\text { Financeira (Alav) }\end{array}$ & $\begin{array}{l}\text { Logaritmo naturaldo } \\
\text { LP/Patrimônio Líquido }\end{array}$ & $\begin{array}{l}\text { Hallak e Silva } \\
(2012), \text { Martinez } \\
\text { e Moraes (2014) } \\
\text { e Castro Peleias } \\
\text { e Silva (2014). }\end{array}$ \\
\hline $\begin{array}{l}\text { Contas a receber } \\
\text { (CtasRec) }\end{array}$ & $\begin{array}{l}\text { Logaritmo natural das Contas } \\
\text { Receber/Ativo Total }\end{array}$ & $\begin{array}{l}\text { Martinez e } \\
\text { Moraes (2014) }\end{array}$ \\
\hline Estoque (Est) & Logaritmo natural do Estoque/Ativo Total & $\begin{array}{l}\text { Martinez e } \\
\text { Moraes (2014) }\end{array}$ \\
\hline
\end{tabular}

Fonte: Adaptado de Pletsch, Cunha e Silva (2015).

Os dados foram coletados e tabulados em planilha eletrônica. Posteriormente, estes dados foram analisados, por meio de estatística descritiva, considerando a frequência observada, a porcentagem, o valor mínimo e máximo, as medidas de tendência central e de variabilidade. O próximo passo contou com a apuração de regressão linear múltipla, tendo como foco identificar a relação entre os honorários de auditoria e as variáveis propostas pelas hipóteses. Osoftware utilizado para esses procedimentos foi IBM SPSSßStatistics version 21.

\section{DESCRIÇÃO E ANÁLISE DOS RESULTADOS}

Nesta seção são apresentadas a descrição e a análise dos resultados da pesquisa. A análise estatística foi iniciada pela descrição dos dados através da frequência observada, porcentagem, valor mínimo, máximo, medidas de tendência central e de variabilidade.

A regressão linear múltipla foi utilizada na associação entre os honorários de auditoria e os possíveis fatores de influência no aumento ou redução da mesma. As premissas de ausência de correlação serial (Durbin-Watson), multicolinearidade (VIF), ausência de heterocedasticidade (Pesarán-Pesarán) e normalidade dos erros (Kolmogorov-Smirnov) foram avaliadas. Para que fossem alcançadas todas as premissas se teve que realizar transformações logarítmicas em todas as variáveis 
(dependente e independente) com exceção das variáveis dicotômicas (dummys), com nível de significância adotado de 5\% e intervalo de confiança de $95 \%$.

A análise descritiva das variáveis do estudo é apresentada no Quadro 06.

Quadro 06 - Análise descritiva das variáveis do estudo

\begin{tabular}{llllll}
\hline Variáveis & Mínimo & Máximo & Mediana & Média & $\begin{array}{l}\text { Desvio } \\
\text { padrão }\end{array}$ \\
\hline LnHonAud & 11,10 & 17,30 & 13,78 & 13,70 & 1,15 \\
LnTam & 17,00 & 26,60 & 22,30 & 22,40 & 1,48 \\
LnSubs & 0,00 & 5,70 & 1,71 & 1,80 & 1,42 \\
LnROA & $-4,60$ & 2,30 & $-2,79$ & $-2,80$ & 1,22 \\
LnAlav & $-3,50$ & 4,80 & $-0,25$ & $-0,20$ & 1,23 \\
LnCtasRec & $-4,60$ & 0,00 & $-2,15$ & $-2,10$ & 1,04 \\
\hline LnEst & $-4,60$ & 0,00 & $-1,52$ & $-1,60$ & 1,46 \\
\hline
\end{tabular}

Fonte: Dados da pesquisa.

Com base no quadro 06, observou-se que a variável logaritmo natural honorários de auditoria (HonAud) apresentou valor mínimo, máximo e média de 11,10, 17,30 e 13,78, respectivamente, com similaridade entre os valores por demonstrar desvio padrão 1,15. A variável tamanho da empresa (Tam), medida pelo logaritmo natural do ativo total, com desvio padrão de 1,48, demonstrou que houve grande discrepância do valor do tamanho da empresa com relação a média de 22,40 . No que tange a complexidade das empresas analisadas (Subs), observou-se que algumas empresas não possuem subsidiárias, enquanto outras apresentaram um número elevado chegando a 313. A variável rentabilidade do ativo (ROA) não apresentou valores similares entre as empresas, no entanto, cabe ressaltar que aproximadamente $33 \%$ das empresas apresentaram valores negativos. A variável alavancagem (Alav), medida pela relação entre dívidas de longo prazo e patrimônio líquido em logaritmo natural, com desvio padrão 1,23 o que indica que a alavancagem das empresas apresenta oscilação, com uma média de -0,20, e também por apresentar valor mínimo de $-3,50$ e valor máximo de 4,80. A variável contas a receber (CtasRec) não teve dispersão de valores entre as empresas, o que pode ser visto no desvio padrão de 1,04. Já a discrepância do desvio padrão do estoque (Est) pode ter sido influenciada em função de $22 \%$ das entidades serem do ramo de serviço não apresentando valor para Estoque de Mercadorias.

Quanto ao tipo de auditoria, as empresas auditadas por Big Four (Big4) correspondem a $78,70 \%$ para sim e $21,30 \%$ para não. A análise da regressão linear múltipla é apresentada no quadro 07.

Quadro 07: Associação entre os honorários de auditoria e os possíveis 
fatores de influência (Regressão linear múltipla)

\begin{tabular}{|c|c|c|c|c|c|c|c|c|c|}
\hline \multirow[t]{2}{*}{ Modelo } & \multirow[t]{2}{*}{ B } & \multirow[t]{2}{*}{$\begin{array}{l}\text { Erro } \\
\text { pa- } \\
\text { drão }\end{array}$} & \multirow[t]{2}{*}{$\begin{array}{c}\text { B } \\
\text { Padroniza- } \\
\text { do }\end{array}$} & \multirow[t]{2}{*}{$t$} & \multirow[t]{2}{*}{$\begin{array}{c}\text { Valor } \\
\mathbf{p}\end{array}$} & \multicolumn{2}{|c|}{$\begin{array}{l}\text { Intervalo de } \\
\text { confiança de } \\
95.0 \% \text { para B }\end{array}$} & \multirow[t]{2}{*}{ VIF } & \multirow[t]{2}{*}{$\begin{array}{c}\text { Rela- } \\
\text { ção }\end{array}$} \\
\hline & & & & & & $\begin{array}{l}\text { Limite } \\
\text { inferior }\end{array}$ & $\begin{array}{l}\text { Limite } \\
\text { superior }\end{array}$ & & \\
\hline (Constante) & 4,047 & 1,231 & & 3,287 & 0,001 & 1,615 & 6,480 & & - \\
\hline $\begin{array}{l}\text { Dummy } \\
\text { GC1 (Sim) }\end{array}$ & $-0,017$ & 0,208 & $-0,005$ & $-0,083$ & 0,934 & $-0,428$ & 0,394 & 1,161 & Nula \\
\hline $\begin{array}{l}\text { Dummy } \\
\text { GC2 (Sim) }\end{array}$ & 0,018 & 0,245 & 0,005 & 0,072 & 0,943 & $-0,466$ & 0,502 & 1,100 & Nula \\
\hline Subs (Sim) & 0,017 & 0,051 & 0,022 & 0,337 & 0,736 & $-0,084$ & 0,118 & 1,092 & Nula \\
\hline LnBig4 & 0,837 & 0,183 & 0,288 & 4,578 & $<0,001$ & 0,476 & 1,198 & 1,064 & Positiva \\
\hline LnTam & 0,415 & 0,058 & 0,514 & 7,186 & $<0,001$ & 0,301 & 0,530 & 1,369 & Positiva \\
\hline LnROA & 0,044 & 0,061 & 0,045 & 0,718 & 0,474 & $-0,077$ & 0,165 & 1,052 & Nula \\
\hline LnAlav & 0,146 & 0,063 & 0,156 & 2,327 & 0,021 & 0,022 & 0,270 & 1,206 & Positiva \\
\hline LnCtasRec & 0,023 & 0,075 & 0,021 & 0,307 & 0,759 & $-0,125$ & 0,171 & 1,216 & Nula \\
\hline LnEst & 0,037 & 0,049 & 0,047 & 0,739 & 0,461 & $-0,061$ & 0,134 & 1,085 & Nula \\
\hline
\end{tabular}

Valor $\mathrm{p}(\mathrm{F})<0,001$

$\mathrm{R}^{2}$ Ajustado $=0,403$

Durbin-Watson $=2,042$

Pesarán-Pesarán $(F)=0,018$ e valor $p=0,893$

Quadro 07: Associação entre os honorários de auditoria e os possíveis fatores de influência (Regressão linear múltipla) (continuação)

Kolmogorov-Smirnov $=0,054$ e valor $p=0,200$ (Limite inferior da significância verdadeira)

Variável dependente - Logaritmo natural dos Honorários da Auditoria.

B - Coeficiente do modelo; $\mathrm{t}$ - Estatística de teste; VIF - Fator de inflação da variância.

Fonte: Dados da pesquisa.

O Quadro 07 apresenta a associação entre os honorários de auditoria e os possíveis fatores de influência. $O$ modelo de regressão foi significante, portanto os fatores influenciam os honorários da auditoria (LnHonAud).

A premissa de ausência de correlação serial (Durbin-Watson) foi satisfeita, ou seja, em torno de 2, pois segundo Marôco (2010), valores próximos a 2 indicam ausência de autocorrelação serial entre os erros. A de multicolinearidade (VIF) ficou em torno de 1, o que resulta em ausência de multicolinearidade (GUJARATI, 2006), a heterocedasticidade não foi confirmada pelo teste de Pesarán-Pesarán, uma vez que o teste não rejeitou a hipótese nula de ausência desta e o teste de KolmogorovSmirnov não rejeitou a normalidade dos resíduos. 
O modelo ajustado consegue explicar os honorários da auditoria em $40,3 \%\left(R^{2}\right)$. Não houve associação das dummys da governança corporativa, das subsidiárias que a empresa possui (Subs), do retorno do ativo (LnROA), das contas a receber (LnCtasRec) e do estoque (LnEst) com os honorários ( $p>0,050)$. No entanto,, houve para as auditadas por Big4 (LnBig4), o tamanho da empresa (LnTam) e a alavancagem financeira (LnAlav) e nestes três casos houve uma relação positiva com os honorários, ou seja, se a empresa foi auditada por Big4, se quanto maior o tamanho da empresa e quanto maior for a alavancagem financeira, maior serão os honorários da auditoria contábil.

Portanto, os achados rejeitam a hipótese principal $(\mathrm{H} 1)$ do estudo, concluindo que não há relação entre os níveis de governança corporativa com os honorários de auditoria contábil. No entanto, tendo em vista que a pesquisa levou em consideração apenas um ano (2015), talvez, o resultado aqui apresentado poderia ser diferente de outros estudos. Essa argumentação explicaria a divergência desse resultado com o que foi destacado por Hallak e Silva (2012), tendo em vista que apontaram uma relação positiva entre as boas práticas de governança corporativa e gastos de auditoria. Por outro lado, esses achados corroboram com os que foram apresentados por Bortolon, Sarlo Neto e Santos (2013), tendo em vista que eles identificaram uma relação negativa entre governança corporativa e os custos de auditoria, sendo efeito do risco o mais predominante. Desse modo, tais evidências destacam a necessidade de realização de novos estudos, que considerem um período maior para a análise.

Por conseguinte, os resultados também rejeitam as hipóteses $\mathrm{H} 2 \mathrm{c}, \mathrm{H} 2 \mathrm{~d}, \mathrm{H} 2 \mathrm{f}$ e H2g, não sendo encontrada relação positiva entre as variáveis: complexidade da empresa, rentabilidade do ativo, contas a receber e estoque com os honorários de auditoria. Desse modo, considerando a amostra estudada e o período de análise, apenas foram aceitas as hipóteses $\mathrm{H} 2 \mathrm{a}, \mathrm{H} 2 \mathrm{~b}$ e H2e. Esses achados demonstram que somente o fato da firma de auditoria ser uma big four, o tamanho da empresa e a alavancagem influenciam, positivamente, os honorários de auditoria. Esses achados se tornam interessantes, tendo em vista que as empresas poderiam considerar essas informações de seus dados contábeis para avaliar possíveis efeitos nos valores que serão cobrados pelas empresas de auditoria. Além disso, as empresas também estariam cientes que os honorários de auditoria seriam maiores se optassem por contratar uma big four.

\section{CONSIDERAÇÕES FINAIS E SUGESTÕES DE PESQUISAS FUTURAS}

Nesta pesquisa, buscou-se analisar a relação entre honorários de auditoria e governança corporativa em empresas listadas na BM\&FBovespa. Para isso foram analisadas 169 empresas segmentadas nos níveis 1, 2 e Novo Mercado da amostra que continha mais informações necessárias para realizar a pesquisa referente ao ano de 2015.

Para verificar a robustez dos resultados foram aplicados os testes de Aleatoriedade, multicolinearidade, heterocedasticidade e normalidade dos resíduos. Por intermédio dos resultados, considerou-se rejeitada a Hipótese $\mathrm{H} 1$ por não haver relação estatisticamente significativa entre governança corporativa com os honorários de auditoria, corroborando com os achados de Bortolon, Sarlo Neto e Santos (2013), que também identificaram uma relação negativa entre governança corporativa e os custos de auditoria, predominando o efeito do risco. Enquanto os achados de Hallak 
e Silva (2012) identificaram uma relação positiva entre as boas práticas de governança corporativa e gastos de auditoria.

Rejeitou-se também as hipóteses $\mathrm{H} 2 \mathrm{c}, \mathrm{H} 2 \mathrm{~d}, \mathrm{H} 2 \mathrm{f}$ e $\mathrm{H} 2 \mathrm{~g}$ por não apresentarem relações positivas e significativas entre a complexidade, o retorno sobre 0 ativo, as contas a receber e o estoque com os honorários de auditoria. Contrariando os estudos de Castro, Peleias e Silva (2014), Martinez e Moraes (2014), Hallak e Silva (2012) e Beck, Cunha e Franz (2015), estes indicam que há uma tendência de que quanto mais complexos forem os clientes maiores os honorários. Entretanto, vai de encontro aos estudos de Martinez, Lessa e Moraes (2014), que apontaram uma relação negativa entre a variável ROA e os honorários. Por outro lado, Martinez, Lessa e Moraes (2014) também concluíram que, no Brasil, as variáveis contas e receber e estoque não fazem com que estes clientes paguem maiores honorários.

No que respeita as restantes hipóteses, foram aceitas as $\mathrm{H} 2 \mathrm{a}, \mathrm{H} 2 \mathrm{~b}$ e $\mathrm{H} 2 \mathrm{e}$, resultando significativamente a relação com os honorários de auditoria das empresas estudadas. Os resultados obtidos demonstram que as empresas auditadas por Big4, o tamanho da empresa e a alavancagem financeira causam impacto positivo e significativo nos honorários de auditoria, ou seja, consequentemente os honorários de auditoria são mais elevados. Similarmente ao encontrado por Bortolon, Sarlo Neto e Santos (2013), Castro, Peleias e Silva (2014), Hallak e Silva (2012) e Beck, Cunha e Franz (2015), que também evidenciaram que quando a auditoria independente é realizada por uma firma Big Four, há uma relação positiva sobre os honorários de auditoria.

Outra evidência positiva está relacionada ao tamanho da entidade e aos honorários, assim como Marques et al. (2014), Munhoz et al. (2014) e Castro, Peleias e Silva (2014), observa-se que a capacidade financeira destes clientes está associada com maiores honorários.

Os resultados alcançados também sugerem que o fator alavancagem financeira da entidade gera influência sobre os honorários cobrados, contrariando os estudos de Hallak e Silva (2012) e Martinez e Moraes (2014), que não encontraram relação, estatisticamente significativa, entre os mesmos. Para Castro, Peleias e Silva (2014), o resultado sugere que os honorários cobrados tendem a ser menores, pelo fato da pressão imposta pelo cliente, com problemas financeiros, sobre os auditores para terem menores custos com auditoria.

Deste modo, objetivando atender as contribuições propostas para este estudo, a pesquisa visou analisar a comparação entre governança corporativas empresas listadas na BM\&FBovespa e seus honorários de auditoria. Porém, a hipótese principal $\mathrm{H} 1$ foi rejeitada por não haver relação estatisticamente significativa entre governança corporativa com os honorários de auditoria. As hipóteses $\mathrm{H} 2 \mathrm{a}, \mathrm{H} 2 \mathrm{~b}$ e H2 foram as que tiveram resultados significativos com os honorários de auditoria, demonstrando que as empresas auditadas por Big4, o tamanho da empresa e a alavancagem financeira causam impacto positivo e significativo nos honorários de auditoria e não sobre a adoção da governança corporativa na entidade. Portanto, é possível concluir que não houve impacto nos honorários de auditoria, quando se comparou a governança corporativa nas empresas listadas na BM\&FBovespa no período da realização desta pesquisa.

Como sugestão de futuras pesquisas se propõe a ampliação da amostra com a inclusão dos segmentos de Governança Corporativa: "Bovespa Mais" e "Bovespa Mais nível 2", o estudo em uma janela temporal superior a 1 (um) ano. Além de estudos e pesquisas sobre teoria da sinalização em relação ao mercado, pois ainda 
é preciso identificar novos meios de sinalização das empresas para com o mercado e seus custos de sinalização gerados, a fim de transparecer cada vez mais suas informações, descobrindo se podem impactar ou não nos honorários de auditoria.

\section{REFERÊNCIAS}

ALMEIDA, J. E. F. DE; ALMEIDA, J. C. G. DE. Auditoria e earnings management: estudo empírico nas empresas abertas auditadas pelas big four e demais firmas de auditoria. Revista Contabilidade \& Finanças, v. 20, n. 50, p. 62-74, 2009.

ANTUNES, M.A.; PROCIANOY, J.L. Os efeitos das decisões de investimento das empresas sobre os preços de suas ações no mercado de capitais. Revista de Administração RAUSP, São Paulo, v.38, n.1, p.5-14, jan./fev./mar. 2003.

AZEVEDO, F. B.; COSTA, F. M. da. Efeito da troca da firma de auditoria no gerenciamento de resultados das companhias abertas brasileiras. Revista de Administração Mackenzie, v. 13, n. 5, p. 65-100, 2012.

BECK, F.; CUNHA, P.R. da; FRANZ, L. Honorários de auditoria: uma análise das empresas familiares e não familiares listadas na BM\&FBovespa. R. bras. Gest. Neg., São Paulo, v. 17, n. 54, p. 720-735, jan./mar. 2015.

BOLSADE VALORES, MERCADORIAS E FUTUROS DE SÃO PAULO (BM\&FBovespa), (2016) Segmentos de listagem. Recuperado em 21 de maio, 2016, de <http://www.bmfbovespa.com.br/pt_br/listagem/acoes/segmentos-delistagem/sobre-segmentos-de-listagem/>.

BORTOLON, P.M.; SARLO NETO, A.; SANTOS, T.B. Custos de Auditoria e Governança Corporativa. R. Cont. Fin. - USP, São Paulo, v. 24, n. 61, p. 27-36, jan./fev./mar./abr. 2013.

BORTOLON, P.M.; SILVA JUNIOR, A. da Delisting Brazilian Public Companies: Empirical Evidence about Corporate Governance Issues. BBR, Vitória, BBR Special Issues, p. 92 - 117. 2015.

CAMARGO, R.V.W.; PEPINELLI, R.C.C.; CAMACHO, R.R. Uma abordagem sobre os riscos de auditoria na emissão do parecer. Semana do Contador 2006, Anais 2006, arquivo 32, Departamento de Ciências Contábeis, Universidade Estadual de Maringá, Paraná, Brasil.

CARCELLO, J. V.; HERMANSON, D. R.; NEAL, T. L.; RILEY JR., R. A. Board characteristics and audit fees. Contemporary Accounting Research, v. 19, n. 3, p. 365-384, 2002. Disponível em: <http://doi.wiley.com/10.1506/CHWK-GMQ0-MLKEK03V>. Acesso em: 18 abr. 2017.

CASTRO, W.B. de L.; PELEIAS, I. R.; SILVA, G. P. da. Determinantes dos honorários de auditoria: um estudo nas empresas listadas na BM\&FBovespa, Brasil. XXXVIII Encontro da Anpad, Rio de Janeiro, 2014. 
CFC. Normas brasileiras de contabilidade: NBC PA - do auditor independente: NBC PA 01, 11, 12, 13, 290 e 291 e Resolução CFC 1.019/05. Brasília: Conselho Federal de Contabilidade, 2012.

CORDEIRO, C. M. R. Auditoria e governança corporativa. Curitiba: IESDE Brasil, 2012.

CUNHA, P. R. DA; BEUREN, I. M.; PEREIRA, E. Análise dos pareceres de auditoria das demonstrações contábeis de empresas de Santa Catarina registradas na Comissão de Valores Mobiliários. RIC-Revista de Informação Contábil, v. 3, n. 4, p. 66-80, 2010.

DALMÁCIO, F. Z. Mecanismos de governança e acurácia das previsões dos analistas do mercado brasileiro: uma análise sob a perspectiva da teoria da sinalização. 2009. Tese Doutorado em Ciências Contábeis, Departamento de Contabilidade e Atuária da Faculdade de Economia, Administração e Contabilidade, Universidade de São Paulo, São Paulo, Brasil.

DAMASCENA, L. G.; FIRMINO, J. E.; PAULO, E. Estudo sobre os pareceres de auditoria: análise dos parágrafos de ênfase e ressalvas constantes nas demonstrações contábeis das companhias listadas na bovespa. Contabilidade Vista \& Revista, v. 22, n. 2, p. 125-154, 2011.

EREIRA, S.M. O relato do risco:uma análise no contexto das empresas cotadas na Euronext Lisbon.2007. Dissertação de Mestrado em Contabilidade e Finanças, Escola superior de tecnologia e gestão, Instituto Politécnico de Leiria, Portugal.

FORMIGONI, H.; ANTUNES, M. T. P.; LEITE, R. S.; PAULO, E. A contribuição do rodízio de auditoria para a independência e qualidade dos serviços prestados: um estudo exploratório baseado na percepção de gestores de companhias abertas brasileiras. Contabilidade Vista \& Revista, v. 19, n. 3, p. 149-167, 2009.

GARCIA, F. A. Governança corporativa. (2005). Monografia de Graduação no Instituto de Economia, Universidade Federal do Rio de Janeiro, Rio de Janeiro, Brasil.

GUJARATI, D.N. Tradução de Maria José Cyhlar Monteiro. Econometria Básica. Rio de Janeiro: Elsevier, 2006.

HALLAK, R.T.P.; SILVA, A.L.C. da. Determinantes das Despesas com Serviços de Auditoria e Consultoria Prestados pelo Auditor Independente no Brasil.R. Cont. Fin. - USP, São Paulo, v. 23, n. 60, p. 223-231, set./out./nov./dez. 2012.

HAY, D. C.; KNECHEL, W. R.; WONG, N. Audit fees: a meta-analysis of the effect of supply and demand attributes. Contemporary Accounting Research, v. 23, n. 1, p. 141-191, 2006. Disponível em: <http://doi.wiley.com/10.1506/4XR4-KT5V-E8CN91GX>. Acesso em: 18 abr. 2017. 
HAY, D.; KNECHEL, W. R.; LING, H. Evidence on the impact of internal control and corporate governance on audit fees. International Journal of Auditing, v. 12, n. 1, p. 9-24, 2008. Disponível em: <http://doi.wiley.com/10.1111/j.10991123.2008.00367.x>. Acesso em: 18 abr. 2017.

IBGC. Código das melhores práticas de governança corporativa. São Paulo: IBGC, 2010.

JESUS, S.M. de; ALBERTON, L. O processo de implementação da governança corporativa nas empresas de capital aberto: um estudo com ênfase na auditoria. Revista Contemporânea de Contabilidade. a.4, v.1, n.8, Jan/Jun, 2007, p. 67-84.

KIRMANI, A.; RAO, A. No Pain, No Gain: A Critical Review of the Literature on Signalling Unobservable Product Quality. Journal of Marketing. v.64, p. 66-79, 2000.

KLANN, R.C.; BEUREN, I.M. Características de empresas que influenciam o seu disclosure voluntário de indicadores de desempenho. BBR- Brazilian Business Review, v. 8, n. 2, p. 96-118, abr./jun. 2011.

LIMA, S.H. de O.; OLIVEIRA, F.D.; CABRAL, A.C. de A.; SANTOS, S.M. dos; PESSOA, M.N.M. Governança corporativa e desempenho econômico: uma análise dos indicadores de desempenho entre os três níveis do mercado diferenciado da BM\&FBovespa.REGE,São Paulo - SP, Brasil, v. 22, n. 2, p. 187-204, abr./jun. 2015.

LINS, L. DOS S. Auditoria: uma abordagem prática com ênfase na auditoria externa. 3 ed. ed. São Paulo: Atlas, 2014.

SILVA, M. de L. A divulgação do risco nas demonstrações financeiras: Uma analise ao anexo das sociedades não financeiras portuguesas. ISACAL Instituto Politécnico de Lisboa, Instituto Superior de Contabilidade e Administração de Lisboa, Lisboa, jan. 2015.

MARÔCO, J. Análise Estatística com o PASW Statistics (ex-SPSS).Report Number, Lisboa, 2010.

MARQUES, M.C.; CONDE, M.F. Teoria da sinalização e da agencia.OROC, Revisores e Empresas, p. 39-45, jul./set. 2000.

MARTINEZ, A.L. Quando o conselho de administração e a auditoria evitam o gerenciamento de resultados? Evidencias empíricas para empresas brasileiras.RIC Revista de Informação Contabil, ISSN 1982-3967, v. 4, n. 1, p. 76-93, jan./mar. 2010.

MARTINEZ, A.L.; LESSA, R.C.; MORAES, A. de J. Remuneração dos auditores perante a agressividade tributária e governança corporativa no Brasil. Revista de Contabilidade e Controladoria, ISSN 1984-6266, Universidade Federal do Paraná, Curitiba, v. 6, n.3, p. 8-18, set./dez. 2014. 
MELO, R.S. de; BATISTA, P.C. de S.; MACEDO, A.C.M. de; COSTA, R.B.L. de. A contribuição da governança corporativa para 0 desempenho das empresas brasileiras de capital aberto.REGE, São Paulo - SP, Brasil, v. 20, n. 1, p. 79-92, jan. /mar. 2013.

MUNHOZ, T.R.; MURRO, E.V.B.; TEIXEIRA, G.B.; LOURENÇO, I. O Impacto da Adoção Obrigatória das IFRS nos Honorários de Auditoria em Empresas da Bovespa. XIV Congresso USP Controladoria e Contabilidade, São Paulo, 2014.

OLIVEIRA, A. Q. DE; SANTOS, N. M. B. F. DOS. Rodízio de firmas de auditoria: a experiência brasileira e as conclusões do mercado. Revista Contabilidade \& Finanças, v. 18, n. 45, p. 91-100, 2007.

OLIVEIRA, J.L.R. de; SOUZA, A.A. de; VIEIRA, C.M. Análise dos fatores envolvidos na estimação de custo e formação de preço nas empresas de auditoria. Contabilidade Vista e Revista, Belo Horizonte,v. 15, n. 2, p. 107-125, ago. 2004.

OLIVEIRA, R. R.; CARVALHO, V. S. DE. A produção científica sobre auditoria: um estudo bibliométrico a partir do caderno de indicadores da CAPES no período de 2004 a 2006. Pensar Contábil, v. 10, n. 42, 2008.

PEREIRA, A. C.; NASCIMENTO, W. S. do. Um estudo sobre a atuação da auditoria interna na detecção de fraudes nas empresas do setor privado no Estado de São Paulo. Revista Brasileira de Gestão de Negócios, v. 7, n. 19, p. 46-56, 2005. Fundação Escola de Comércio Álvares Penteado.

PEREZ JÚNIOR, J. H. Auditoria de demonstrações contábeis: normas e procedimentos. 5 ed. ed. São Paulo: Atlas, 2012.

RICARDINO, Á.; CARVALHO, L. N. Breve retrospectiva do desenvolvimento das atividades de auditoria no Brasil. Revista Contabilidade \& Finanças, v. 15, n. 35, p. 22-34, 2004. SciELO Brasil.

SANTOS, A. C.; SOUZA, M. A.; MACHADO, D. G.; SILVA, R. P. DA. Auditoria independente: um estudo dos pareceres emitidos sobre demonstrações contábeis de empresas brasileiras listadas na Bovespa e na Nyse. Revista Universo Contábil, v. 5, n. 4, p. 44-62, 2009.

SANTOS, J. dos; DINIZ, J. A.; CORRAR, L. J. O foco é a teoria amostral nos campos da auditoria contábil tradicional e da auditoria digital: testando a Lei de Newcomb-Benford para o primeiro dígito nas contas públicas. BBR-Brazilian Business Review, v. 2, n. 1, p. 71-89, 2005. FUCAPE Business School.

SILVEIRA, A. Di Miceli da; PEROBELLI, F.F.C.; BARROS, L.A.B. de C. Governança corporativa e os determinantes da estrutura de capital: evidências empíricas no Brasil. RAC, Curitiba, v. 12, n 3, p. 763-788, jul./set. 2008.

SIMUNIC, D. A.; STEIN, M. T. The impact of litigation risk on audit pricing: a review of the economics and the evidence. Auditing, v. 15, n. Supplement, p. 132-134, 1996. 
origsite=gscholar $\& \mathrm{cbl}=31718>$. Acesso em: 18 abr. 2017.

SPENCE, M. Job Market Signaling.The Quarterly Journal of Economics. v. 87, n. 3, p. 355-374, Aug. 1973.

VIEIRA, K.M.; LOSEKANN, V.L.; VELASQUEZ, M.D.P.; CERETTA, P.S. A influência da governança corporativa no desempenho e na estrutura de capital das empresas listadas na Bovespa. Revista Universo Contábil, ISSN 1809-3337, FURB, v. 7, n. 1, p. 49-67, jan./mar., 2011.

YATIM, P.; KENT, P.; CLARKSON, P. Governance structures, ethnicity, and audit fees of Malaysian listed firms. (R. Haniffa, Ed.) Managerial Auditing Journal, v. 21, n. $7, \quad$ p. 757-782, 2006. Disponível em: <http://www.emeraldinsight.com/doi/10.1108/02686900610680530>. Acesso em: 18 abr. 2017.

YOSHITAKE, M. Auditoria contábil. Curitiba: IESDE Brasil, 2012.

ZIBORDI, C. de M.A. Os níveis diferenciados de práticas de governança corporativa da Bovespa. XV Seminário de Iniciação Cientifica PUC-RIO, Relatórios Anuais, Departamento de Direito, PUC RIO, Rio de Janeiro, ago. 2015. 